\title{
Labor revolucionaria y problema religioso en el Constituyente de 1916-1917. Un estudio de la dinámica parlamentaria
}

\author{
Revolutionary Efforts and Religious Problems \\ in the Constituent Congress of 1916-1917. \\ A study of Parliamentary Dynamics
}

\author{
María Luna Argudín \\ Universidad Autónoma Metropolitana \\ Unidad Azcapotzalco, México \\ (D) orcid.org/0000-0003-3325-8238 \\ lunita_1981@yahoo.com
}

Resumen: El Congreso Constituyente de 1916-1917 discutió un amplio programa de secularización de la sociedad mexicana, con el que los diputados pretendieron suprimir la influencia política y social del clero. La asamblea pronto se dividió en dos amplias coaliciones: una, defendió las garantías individuales y el endurecimiento de las Leyes de Reforma; la otra, pugnó por transformar la cultura de los mexicanos para erradicar la superstición y el fanatismo, que consideraron propios del catolicismo. El presente artículo mediante el análisis de los grupos políticos en los que se dividió la asamblea, las alianzas y coaliciones que formaron los diputados y las presiones externas -tanto nacionales como las derivadas por la Gran Guerra- a las que estuvieron sometidos, reconstituye la dinámica parlamentaria, que permitió construir consensos entre los diputados para redefinir las libertades de enseñanza y de conciencia y las relaciones entre el poder público y las asociaciones religiosas.

Palabras clave: anticlericalismo; Iglesia católica; Congreso Constituyente; Constitución de 1917; revolución mexicana. 
Abstract: The Constituent Congress of 1916-1917 discussed an extensive program to secularize Mexican society, through which delegates attempted to eliminate the clergy's political and social influence. The assembly soon divided into two broad coalitions. One defended individual guarantees and the stiffening of Reform Laws, while the other sought to transform Mexican culture to eradicate superstition and fanaticism, which they regarded as features of catholicism. This article analyzes the political groups into which the assembly was divided, the alliances and coalitions formed by the delegates, and the external pressures - both national and those resulting from the Great War- to which they were subjected. It does so to reconstitute the parliamentary dynamics that made it possible to achieve consensus between the delegates to redefine freedoms of teaching and conscience and the relationships between the public authorities and religious associations.

Key words: anticlericalism; catholic Church; Constituent Congress; 1917 Constitution; Mexican revolution.

Fecha de recepción: 2 de septiembre de 2016 Fecha de aceptación: 6 de enero de 2017

Para Alejandro, Diego, Ale, Jeró y Fiona que algo heredamos de los bisabuelos.

\footnotetext{
A 1 debatirse la libertad de conciencia en el Congreso Constituyente, el 1 diputado Alonzo Romero indicó: "se ha dicho en esta tribuna que mientras no se resuelva el problema agrario, no se habrá hecho labor revolucionaria, y yo agrego que mientras no se resuelva satisfactoriamente el problema religioso, mucho menos se habrá hecho labor revolucionaria" (Nueva edición, t. I, p. 972). ${ }^{1}$ El diputado indicaba así el antagonismo entre las dos grandes

${ }^{1}$ Para este artículo se ha consultado la Nueva edición del Diario de los debates del Congreso Constituyente de 1916-1917 (2006). Para esta estupenda edición Ignacio Marván Laborde recopiló los decretos referentes al Constituyente, recuperó los dictámenes y sesiones faltantes en otras ediciones e introdujo un sintético y crítico comentario que precede al debate de cada artículo constitucional. Asimismo reprodujo los planes políticos y documentos que contextualizan los debates. En adelante los debates se citarán como $N E$, seguido del tomo y página correspondiente. Los comentarios de Marván se citarán sin modificar el sistema de referencias APA.
}

\section{()(1) $\$$}


coaliciones en las que se dividió la asamblea. Una, arraigada en la tradición, propuso mantener el carácter liberal de la Constitución de 1917 y endurecer la aplicación de las Leyes de Reforma. La otra apuntó a una dimensión más profunda: transformar la cultura cristiana de los mexicanos.

Al celebrarse el centenario de la Constitución de 1917 los historiadores han respondido a una amplia convocatoria para revisar los orígenes del marco jurídico institucional que rige al país. ${ }^{2}$ El presente artículo abona modestamente al debate con el estudio de la dinámica parlamentaria; para ello se analizan los debates en torno al derecho a la educación, las obligaciones de los mexicanos, el derecho a la libertad de conciencia y las relaciones del Estado con las asociaciones religiosas. Los debates señalados fueron elegidos porque al discutir las relaciones entre la Iglesia y el Estado resultaron controversiales por su acendrado anticlericalismo. ${ }^{3}$ Precisamente su sentido

${ }^{2}$ La Constitución de 1917 es uno de los temas más socorridos de la historiografía, pues frecuentemente se ha abordado como la culminación de la revolución mexicana. Entre los autores que han estudiado específicamente al Constituyente de 1916-1917 destacan las crónicas testimoniales de Bojórquez (2014) y Palavicini (1987). Entre los historiadores sobresalen Smith (1973), que analizó la conformación del Congreso; Ulloa (1979), que estudió los debates constitucionales; de manera más reciente destacan los trabajos de Marván, mismos que se encuentran referenciados en la bibliografía de este artículo. Asimismo Marván (2006, vol. III) ofrece una útil guía historiográfica.

${ }^{3}$ Tema siempre polémico - que aún hoy en día despierta pasiones y partidismos- ha sido el anticlericalismo mexicano y su expresión en el Constituyente de Querétaro. Una amplísima historiografía aborda al Congreso extraordinario como antecedente de la guerra Cristera (1926-1929). En ese sentido es interesante el estudio historiográfico de Mabry (1978) que evalúa las obras pioneras del revisionismo académico sobre la guerra cristera y el anticlericalismo revolucionario. Destaca el análisis que hace de Olivera Sedano, Aspectos del conflicto religioso de 1926 a 1929: antecedentes y consecuencias (1966); Quirk, The Mexican Revolution and the Catholic Church, 1910-1929 (1973) y Meyer, La cristiada (1972-1974). Guía indispensable sobre la historia de la Iglesia católica es la elaborada por García Ugarte y Rosas Salas (2016), quienes indican las principales líneas de investigación, autores y obras destacadas publicadas entre 1960 y 2010. Los autores muestran que los estudios sobre el siglo xix y primera mitad del xx se han concentrado en tres ejes temáticos: a) las relaciones Iglesia-Estado, desde una perspectiva política; b) la participación política y social de la Iglesia de 1911 a 1914, conocido como catolicismo social; y en particular se ha analizado el movimiento armado católico de 1926-1929 y los acuerdos firmados en 1929, que restablecieron la paz en el país. Este estudio ofrece las referencias de otros importantes recuentos sobre la historia de las relaciones Iglesia-Estado. Interesante es el breve estado de la cuestión de Butler (2004), quien evalúa las aportaciones de los pioneros del revisionismo académico señalados, concentrándose en la historiografía anglosajona y mexicana indica los logros de la historia regional y de los estudios culturales sobre la religiosidad y anticlericalismo populares (pp. 1-49). Bantjes (2009) ofrece un apretado y lúcido análisis historiográfico de los orígenes culturales y desarrollo del anticlericalismo mexicano revolucionario.

\section{(ㅇ)(1) $(3$}


polémico permite conocer los grupos políticos en los que se dividió la asamblea, las alianzas y coaliciones que formaron los diputados y las presiones externas -tanto nacionales como las derivadas por la Gran Guerra-a las que estuvieron sometidos. Para reconstituir la dinámica parlamentaria se revisa brevemente la conformación del Congreso y de manera puntual se sigue el proceso legislativo (iter legis). Con base en este análisis se afirma que fue en la interacción de ambas coaliciones que la Constitución de 1917 al redefinir las relaciones entre el poder público y las asociaciones religiosas rompió con el modelo liberal de la Constitución de 1857.

\section{MILITARES Y ABOGADOS, ANTICLERICALES TODOS}

El 15 de septiembre de 1916, Venustiano Carranza, primer jefe del Ejército Constitucionalista, convocó a un Congreso extraordinario con el mandato de actualizar la Constitución de 1857 respetando su espíritu liberal. La convocatoria al Congreso Constituyente (Convocatoria, 2016) restringió el trabajo legislativo al proyecto de reformas que presentó Carranza, una vez que se instaló la asamblea el 1 de diciembre.

La misma convocatoria aseguró que la composición política de la asamblea fuera homogénea, pues puso como condición que para ser diputado se requería haber demostrado "con hechos políticos su adhesión a la causa constitucionalista" (art. 8); así, prohibió la participación a todo aquel que se hubiera opuesto a la facción revolucionaria triunfante. La convocatoria introdujo un candado adicional: los diputados electos debían calificar sus credenciales entre sí -autocalificación-, en otras palabras juzgarían su lealtad a Carranza y su legitimidad revolucionaria. El Reglamento Interior del Congreso General (Reformas, 2006), además, limitó las iniciativas de grupos ajenos a la asamblea.

Con todos estos candados no es de extrañarse que entre los diputados impere la coincidencia en diagnósticos y propuestas, pero todavía hay dos motivos adicionales: los orígenes sociales de los representantes son similares y fundamentalmente - como ha señalado Marván (2007)- comparten una misma experiencia política-jurídica debido a que, en mayor o menor medida, en el llamado periodo preconstitucionalista (1915-1916) elaboraron o implementaron la legislación revolucionaria, publicada por Carranza y los principales jefes revolucionarios en sus áreas de influencia. Pese a ello, en estas

\section{(1)(1) $\$$}


páginas se enfatizan los matices y las diferencias entre los grupos políticos, como se verá más adelante.

En cuanto a los orígenes de los representantes destaca que la mayoría (casi $85 \%$ ) se reconocen como clase media provinciana y pocos de clase baja (12\%), categorías de uso cotidiano, pero poco rigurosas (Smith, 1973, p. 364). De los 218 diputados activos en el Congreso, 61 eran abogados o contaban con estudios de derecho (28\%), formaban parte de la clase política que emergió con la revolución, y que "tomó literalmente los cargos públicos del país después de la derrota político-militar del viejo régimen, en junio de 1914" (Marván, 2012, p. 3). De los constituyentes 53 eran militares (24.31\%), pero no forman un cuerpo castrense sino un ejército revolucionario -en su mayoría de origen rural- forjado en la guerra civil. El resto era un conjunto variopinto: ingenieros $(9 \%)$, médicos (9\%), maestros (7\%) y otras profesiones y oficios (Marván, 2012, p. 3). La historiografía revisionista -Smith (1973), Marván (2007) entre otros investigadores- ha insistido en que no hay una relación directa entre el origen social, la profesión o la procedencia geográfica de los diputados y la manera en que votaron en el Constituyente. A ello, debe añadirse que tampoco hay correlación entre facciones y creencias religiosas.

Es posible distinguir tres grandes grupos políticos. Uno moderado, que se integraba con 23 diputados que durante el gobierno de Francisco I. Madero pertenecieron al "Bloque Renovador" de la XXVI Legislatura. Forman la elite del Congreso, que se distingue por su amplia cultura humanista, misma que resienten los diputados con otros orígenes sociales como Enrique Recio o Enrique Colunga, incluso este último llega a afirmar que "los hombres cultos son los retardatarios y los intelectuales son los peligrosos" (NE, t. III, p. 2551).

Entre los moderados destacaban los colaboradores cercanos a Carranza. Asociados a la Sección de Legislación Social -que dependía de la Secretaría de Instrucción Pública- elaboraron los proyectos de reforma comprometidos en las adiciones al Plan de Guadalupe del 12 de diciembre de 1914. El ingeniero y periodista Félix F. Palavicini estuvo al frente de la dependencia y en ella participaron los abogados José Natividad Macías -rector de la Universidad-, Luis Manuel Rojas y Alfonso Cravioto. Para redactar las modificaciones a la Constitución, Carranza designó a Macías y Rojas (Rouaix, 1959, p. 46). Este grupo compacto intentó dominar los primeros debates y en especial el relativo al derecho a la educación $\left(\operatorname{art} .3^{\circ}\right.$ ) con su experiencia parlamentaria previa, su profundo conocimiento del proyecto de reformas y del reglamento de la asamblea constituyente. Pero esta ventaja disminuye a medida que la

\section{()(1) $\circledast$}


mayoría de los diputados aprende a "batirse en la tribuna y fuera de ella" (Bojórquez, 2014, p. 399).

La segunda facción era más radical y estaba formada con los leales a Álvaro Obregón, Blidstein (2000) estima que no sumaron más de 17 personas (p. 44), pero su influencia, aunque se concentra en la diputación sonorense, se extiende a otros representantes. Así, al debatirse el artículo $3^{\circ}$, Rojas denuncia al pleno que el periódico Gladiador publicó un telegrama del general dirigido a los diputados de Jalisco y de Occidente para que mantuvieran una actitud intransigente (NE, t. I, p. 166). Mientras que los moderados tenían como publicista a Palavicini, que fundó en 1916 el periódico El Universal como eficaz medio de propaganda, los obregonistas contaban con Juan de Dios Bojórquez, cuya Crónica del Constituyente -publicada en 1938- por largo tiempo determinó la interpretación histórica del Congreso extraordinario exagerando el papel que desempeñó su grupo político.

La inmensa mayoría son diputados independientes que formaron alianzas y coaliciones con base en coincidencias temáticas. Hay evidencias de que Carranza influyó en los comicios para que resultaran electos sus más cercanos colaboradores, pero otros como el general Mújica, contaban con sus propias bases sociales y militares. Aunque aún hacen falta mayores estudios regionales que permitan trazar un mapa preciso del proceso electoral en los distritos, Blidstein (2000) propone que la gran mayoría de los diputados eran notables locales o regionales que se articulaban con un estrato de mandos intermedios de comandantes militares y gobernadores, a quienes deben directamente su elección al Constituyente. Por eso sin tratarse de un mandato imperativo, algunos representantes llegan al Congreso con instrucciones precisas de los gobernadores sobre las iniciativas que deben apoyar.

En la asamblea campea un acendrado anticlericalismo que tiene muy diversos orígenes. Matute (2008) ha sugerido que entre los diputados obreros y obreristas se mantiene viva la herencia del Plan y Programa del Partido Liberal (1906), que se actualiza -entre otros motivos- por el acelerado crecimiento del catolicismo social bajo los gobiernos de Francisco I. Madero y Victoriano Huerta, perdurando así la exigencia de endurecer la aplicación de las Leyes de Reforma, nacionalizar los bienes del clero y suprimir la injerencia del clero en la educación (p. 32). Estas demandas básicas en la asamblea son potenciadas por las creencias íntimas de los diputados; ahí convivieron librepensadores -como Mújica y Palavicini-, positivistas -como Hilario Medina-, connotados francmasones -Rojas en los años veinte llegaría a ser Gran Maestro de la Logia del Valle de México- y algún bolchevique como

\section{()(1) $(3$}


Luis G. Monzón. Entre los diputados hay también protestantes (bautistas y metodistas), espiritistas y quizá teósofos, religiones y formas filosóficas que se difundieron entre los círculos liberales a partir de la segunda mitad del siglo XIX (Urias Horcasitas, 2008, pp. 198-199). Marginales, aunque no marginados, no se atreven a manifestar sus creencias abiertamente.

Los grupos políticos señalados forman dos inestables coaliciones. Una -que mantiene como núcleo a los moderados-defiende las libertades individuales. Mientras que la jacobina se inclina por consolidar una revolución cultural que erradique los efectos que considera negativos del catolicismo: la superstición, el fanatismo y la influencia política y social del clero.

Son muy pocos los diputados que suben a la tribuna, lo que propicia que un puñado adquiera un papel protagónico. Destacan Palavicini como vocero de la facción moderada; Mújica y Medina, ambos miembros de las comisiones de dictamen, el general michoacano principal redactor de las reformas al artículo $3^{\circ}$ y Medina del 130 . No obstante, en sus intervenciones -cabe advertir- se confunden las posiciones de los grupos a los que pertenecen con sus personales convicciones políticas e irreligiosas $\mathrm{y}$, como buenos oradores, echan mano de recursos actorales, retóricos y lugares comunes para arrancar aplausos y sumar votos.

\section{LOS TINTES DEL LAICISMO}

El 13 de diciembre de 1916, tras aprobar por unanimidad los artículos $1^{\circ}$-que establece "En la República Mexicana todo individuo gozará de las garantías que otorga esta Constitución" - y el $2^{\circ}$-que prohíbe la esclavitud-, inicia el debate sobre el derecho de los mexicanos a la educación. El dictamen de la Comisión de Reformas del 9 de enero de 1917 perfila tres proyectos distintos: uno sometido a la asamblea por Venustiano Carranza, otro propuesto por la dictaminadora -integrada con Francisco J. Mújica, Enrique Colunga, Luis G. Mozón, Enrique Recio y Alberto Román-y un tercero contenido en el voto particular del profesor Monzón.

El proyecto del primer jefe defiende la libre enseñanza -como la estableció la Constitución de 1857- pero introduce un control del Estado: la enseñanza que impartan las escuelas estatales será laica y la educación primaria oficial además será gratuita.

Cravioto explica que el artículo propuesto conjuga dos ámbitos: la garantía individual y las obligaciones del Estado. Fundamenta el primero

\section{(1)(1) $\$$}


con los atributos inherentes del hombre: pensar no es un derecho, es una ley natural "que sacude nuestra bestialidad y nos enaltece". La libertad de enseñanza se deriva de la más importante y fecunda de todas: la libertad de opinión. "Si el hombre tiene el derecho innegable para escoger temas para su pensamiento y motivos para sus creencias, tiene pues derecho innegable de aprender". De la misma manera si tiene derecho a expresar sus pensamientos y creencias -libertad de opinión-, tiene derecho a enseñar. El derecho de los niños a aprender, al ser menores de edad, recae en el padre para decidir sobre la enseñanza de sus hijos (NE, t. I, p. 186). Concibe las obligaciones del Estado desde un liberalismo de corte clásico que otorga al poder público una intervención mínima en la sociedad. Facultado para fomentar la cultura, el poder público en el campo educativo se limita a suplir las deficiencias de la iniciativa privada, por eso exige a la población un mínimo de instrucción y abre y sostiene el número de escuelas suficiente. Pero, "el Estado que es neutral en asuntos de Iglesia, debe permanecer también neutral en cuestiones de enseñanza" (NE, t. I, p. 186).

La iniciativa de hecho retoma la experiencia porfiriana y propone elevar a rango constitucional las resoluciones del Primer Congreso de Instrucción Pública (diciembre de 1889-marzo de 1890), que fue presidido por Justo Sierra y que tuvo por vicepresidente al pedagogo Enrique Rébsamen. En aquella reunión los representantes de los estados acordaron adoptar un solo programa educativo para toda la república y que la educación tuviera un carácter gratuito, obligatorio y laico. El concepto de instrucción fue sustituido por el de educación, que implicaba el desarrollo armónico e integral del niño -que preveía una formación moral sin religión-. Los resolutivos, a su vez, complementaron la Ley de Instrucción Obligatoria del 23 de mayo de 1888, que dio ese carácter a los cuatro años de estudios de educación primaria elemental para los niños y niñas entre 6 y 12 años de edad (Loyo y Staples, 2012, p. 137).

El dictamen de la Comisión de Reformas rechaza enérgicamente el proyecto para proponer que la educación primaria impartida tanto por el Estado como por particulares sea laica. Con base en una peculiar psicología infantil, la comisión argumenta: la enseñanza religiosa deforma el espíritu de la infancia. El niño al no poder asimilar los dogmas religiosos "quedan en su espíritu en la categoría de sentimientos, se depositan ahí como gérmenes prontos a desarrollarse en un violento fanatismo. Esto explica el afán del clero de apoderarse de la enseñanza, principalmente de la elemental" (NE, t. I, pp. 152-153).

Las ideas saben a viejo. El meollo del dictamen es garantizar para el Estado la formación de las mentes y de las lealtades de los futuros ciudadanos.

\section{()(1) $\$$}


Sierra había resuelto esta vieja problemática con la Ley de Instrucción Primaria de 1908. La educación debía ser laica -entendida como neutral frente a todas las creencias religiosas-, nacional para formar ciudadanos en el amor a su patria y a sus instituciones. De acuerdo con los preceptos de Rébsamen, la formación de los educandos sería intelectual, física y estética y se enseñaría cultura moral, en lugar de religión (Loyo y Staples, 2012, p. 141).

El dictamen rechaza la definición de educación laica porfiriana: la enseñanza no debe ser neutral frente a las creencias religiosas sino que, por el contrario, debe trasmitir la verdad basada en criterios científicos. Propone entonces que la educación primaria sea laica y obligatoria para todos los mexicanos. Gratuita en los establecimientos oficiales. Prohíbe a las corporaciones religiosas y ministros de cualquier culto dirigir o impartir enseñanza. Las escuelas privadas quedan bajo la vigilancia del gobierno (NE, t. I, p. 154).

El potosino profesor Monzón en su voto particular es más radical y propone que la educación en lugar de ser laica sea racionalista. Arremete contra la noción de laicismo porfiriano -instituido en la Ley de 1908- pues considera que el maestro en el aula está obligado a "respetar estrictamente las ideas religiosas del hogar, por erróneas, absurdas e irracionales que sean". En contraste sostiene que la enseñanza del siglo xx debe combatir en todos sus reductos el error, la superstición y el fanatismo (NE, t. I, p. 156). El medio es la educación racionalista -también conocida como Escuela Nueva o Moderna- basada en las ideas del educador catalán Francisco Ferrer i Guardia, corriente que llegó a México a través de las prédicas y escritos anarquistas, que fueron incorporadas al ideario de la Casa del Obrero Mundial (Loyo y Staples, 2012, p. 157).

Al estar reunido el Constituyente, la Escuela Nueva es apenas una propuesta que el profesor José de la Luz Mena comenzó a impulsar en el Primer Congreso Pedagógico de Yucatán (1915), pero llega a discutirse en el Congreso extraordinario gracias al apoyo del general constitucionalista Salvador Alvarado, quien instruyó a la diputación yucateca para que pugnara a favor de la educación racionalista (Mena, 1941, p. 188). El profesor no sólo retoma las experiencias de Ferrer sino también la pedagogía de John Dewey y Oliverio Decroly para apostar por la libertad de los niños de ambos sexos, el aprendizaje mediante la experimentación y el trabajo en laboratorios, talleres y granjas (Mena, 1941, pp. 172-173 y 176). Rasgo distintivo de la educación racionalista es que la escuela en lugar de ser un medio de reproducción social prepara a los educandos para el autogobierno, los introduce al cooperativismo -a través cajas de ahorro, banco escolar, inserción en sindicatos, etc.- y

\section{()(1)}


rechaza la moral dogmática derivada de las religiones, para hacer de la solidaridad la base moral de la sociedad (Mena, 1941, p. 41).

Pese a que el voto particular de Monzón no fue secundado por la asamblea, Mena abriría en septiembre de 1917 la primera escuela racionalista en la ciudad de Mérida, Yucatán, con el apoyo del general Alvarado, que integra esta modalidad educativa a su "reforma social" orientada a transformar los hábitos de trabajo de la población y los valores sociales -combate al alcoholismo, la prostitución, la superstición religiosa y la opresión de las mujeres (Urias Horcasitas, 2008, p. 182)-. Bajo el gobierno de Felipe Carrillo Puerto en 1922 la educación racionalista se convertiría en la escuela oficial del estado (Mena, 1941, p. 22).

El núcleo del "espectacular debate" en el Constituyente -como lo calificara Palavicini- es simple: a los maestros y escuelas privados debe o no debe permitírseles brindar una instrucción religiosa. Pese a su aparente sencillez, las discusiones permiten acceder a otros aspectos del Congreso: a la dinámica parlamentaria y a las demandas por una mayor secularización de la sociedad mexicana que exige la coalición jacobina.

\section{LA DINÁMICA PARLAMENTARIA, ENTRE EL ENFRENTAMIENTO Y LA CONCERTACIÓN}

El 13 de diciembre inicia el debate del artículo $3^{\circ}$ con el primer jefe como testigo que, quizá, acude a la sesión para respaldar con su presencia su proyecto de reformas frente a las tendencias más radicales que se expresaron en la calificación de las elecciones de los diputados, lo cierto es que queda invitado a no volver.

Durante más de cinco horas de intensa discusión entre reproches y ataques personales, se fijan posiciones. Por primera vez se utilizan los calificativos jacobinos y moderados. Mújica se revela como jacobino y "líder de las mayorías" -según recuerda Bojórquez (2014, p. 506).

El debate sobre la libertad de enseñanza es en buena medida una prolongación de las sesiones preparatorias en que se calificaron credenciales. Entonces se recriminó a quienes participaron en la Sección de Legislación Social por mantenerse como diputados en la maderista XXVI Legislatura después del golpe de Estado de Victoriano Huerta. El reproche dio en el núcleo de la legitimidad constitucionalista -es de sobra conocido-que descansaba en el Plan de Guadalupe (1913), con el que Venustiano Carranza se pronunció en

\section{()(1) $(9$}


contra del gobierno de Huerta, considerado usurpador. Ante la tensión en la asamblea, el primer jefe tuvo que respaldar a sus colaboradores con un telegrama en el que afirmó que por instrucciones suyas habían continuado en sus escaños (Palavicini, 1987, vol. 1, p. 123).

El debate sobre la enseñanza resulta por demás agresivo y desordenado, los congresistas discuten la arquitectura de la Constitución, los límites del Estado en las garantías individuales, la influencia social del clero y la gobernabilidad que emanará del nuevo marco institucional.

Por encima de las diferencias, todos se muestran de acuerdo en que "bajo la tolerancia de la dictadura" el clero pacientemente ha buscado "restablecer su poderío por encima de la autoridad civil". Esta tendencia regresiva debe detenerse -según asienta el dictamen (NE, t. I, p. 154). Este argumento central para la coalición jacobina merece un breve paréntesis.

Bajo el gobierno de Díaz las congregaciones religiosas efectivamente se multiplicaron (pasaron de ocho en 1851 a 18 en 1910) y se fundaron nuevos institutos científicos y filosóficos tomistas y escuelas de artes y oficios católicos, pero el total de escuelas oficiales (sostenidas por el gobierno federal, de los estados y municipios) era de 9620 , mientras que las escuelas sostenidas por el clero apenas sumaron 586, según las estadísticas de 1907 que Cravioto muestra al pleno (NE, t. I, p. 188).

La influencia social del clero tiene otra cara -presente entre los diputados- a la que no se refieren explícitamente en los debates: el catolicismo social. La jerarquía eclesiástica, basada en las directrices pastorales de la encíclica Rerum Novarum (1891), aspiró a competir con las instituciones seculares mediante una sólida organización paralela: escuelas y círculos de estudios, organizaciones obreras y ligas agrarias. No sólo los constitucionalistas rivalizaron por las mismas bases sociales, sino que además los operarios guadalupanos en la Semana Social de 1909 presentaron notables coincidencias con las demandas magonistas, liberales y de los obreros anarcosindicalistas (Ceballos Ramírez, 1991, pp. 285-288). El beligerante brazo político eclesiástico, el Partido Católico Nacional (1911-1914), buscó la "reforma constitucional sobre la base de libertad religiosa", libertad efectiva de enseñanza para la Iglesia y la aplicación de la doctrina social cristiana para resolver los problemas sociales (Romero de Solís, 1994, p. 126). Pese a que el episcopado mexicano huyó del país en 1914 acusando a los constitucionalistas de haber desatado la "persecución religiosa", la jerarquía eclesiástica había demostrado su enorme influencia y capacidad organizativa en una sociedad mayoritariamente católica. 
Frente a "la amenaza clerical", los grupos políticos en el Congreso se esfuerzan por alcanzar un acuerdo el 14 de diciembre. El director de El Universal ofrece disculpas a la comisión, Mújica a los exrenovadores. Palavicini (1987) acepta que serán laicas las escuelas oficiales y privadas; a cambio, la comisión retira la prohibición de enseñar a las personas que pertenezcan a alguna asociación religiosa. El periodista propone que el control al clero se complementará con el artículo 27, que en el proyecto de reformas incorpora como antecedente las Leyes de Reforma y, por lo tanto, impide a las corporaciones religiosas dirigir y administrar escuelas (Palavicini, 1987, vol. 1, p. 254).

El punto de acuerdo presenta una segunda faceta: ratificar la unidad revolucionaria en torno a la autoridad del primer jefe. Ello no es poca cosa, pues el forcejeo entre Álvaro Obregón y Venustiano Carranza por influenciar y aun controlar al Congreso mediante alianzas y coaliciones se expresa en el debate sobre la enseñanza. Por eso, Palavicini (1987) propone que la comisión integre las modificaciones necesarias, pero sin el lenguaje rudo al primer jefe. Mújica cierra el trato y reconoce que "la comisión ha cometido una falta muy grave con ese hombre que merece todos mis respetos" y en seguida el general retira el dictamen para quitarle "esas palabras que escuecen" (Palavicini, 1987, vol. 1, pp. 269-270). Efectivamente, la comisión cambia la redacción del dictamen en el sentido propuesto por el periodista, en lugar de asentar que "desecha de plano el proyecto del artículo $3^{\circ}$ presentado por el Primer Jefe", indica que aprueba reformado el proyecto de reformas (NE, t. I, p. 267). La asamblea acuerda continuar el debate dos días después, el 16 de diciembre.

La concertación se lleva a cabo tras bambalinas. La comisión consultó a "una asamblea privada" a la que asistieron incluso algunos diputados que estaban en contra del dictamen. Ahí resolvieron que la prohibición al clero para financiar o dirigir colegios no podría incluirse en el artículo 27 -que aún no dictaminaba, porque se refiere a la propiedad-pero tampoco podría incorporarse en ningún otro. En cambio, en el artículo sobre la educación tiene un fundamento lógico, según explica Mújica al pleno (NE, t. I, pp. 268, 275). Palavicini (1987) en su Historia del Congreso Constituyente ofrece otra versión: "la comisión temerosa de una nueva derrota" recogió las firmas de los diputados en sus alojamientos, así "cuando presentó su dictamen modificado resultaba innecesario el debate porque la votación estaba ganada de antemano" (vol. 1, p. 265).

Más allá de cómo se concertó el artículo, las intervenciones hechas durante la tercera sesión poco añaden al debate, excepto porque los moderados se atrincheran en la defensa de la estructura del texto constitucional. Los

\section{(1)(1) $\$$}


catedráticos de derecho público pugnan, sin éxito, por mantener el orden, jerarquía y la organicidad del instrumento jurídico que servirá para reconstruir al país y como carta de presentación para que México se reintegre al concierto internacional. Rojas y Palavacini -como se ha señalado- defendieron que las limitaciones al clero en materia de enseñanza se integraran en el artículo 27; Lizardi hace un nuevo intento y propone que se incluyan en el último capítulo, que se ocupa de las relaciones entre el poder público y la Iglesia (NE, t. I, p. 316).

Contra estos buenos argumentos, González Torres expresa una postura que poco a poco se impone en la asamblea: "¿Por qué no hemos de ser los primeros que presentemos una Constitución en cierta forma fuera de los principios jurídicos, pero de acuerdo con las necesidades prácticas de la República?" (NE, t. I, p. 319). Defiende así que la nueva ley fundamental no sólo enuncie principios generales sino que reglamente algunos aspectos. Esta posición se fortalece en el debate de la libertad del trabajo (art. $5^{\circ}$ ), pues al no satisfacer las expectativas de la asamblea es necesario elaborar un capítulo especial para proteger a los trabajadores. El artículo 123 efectivamente reglamenta la jornada laboral, el salario mínimo y un largo etcétera, aspectos que Macías considera que son propios de un código obrero - que él mismo ya tiene elaborado-, pero no de la Constitución (Palavicini 1987, vol. 1, p. 300).

El artículo $3^{\circ}$ que se somete a votación se limita a prohibir la enseñanza religiosa en la educación primaria y señala que las escuelas públicas serán gratuitas. A favor votan 100 diputados (64.1\%), en contra 56 (35.9\%) (Marván, 2006, t. 1, p. 340).

Prudencia, predican los moderados con insistencia. Rojas recuerda al pleno que al promulgarse la Carta de 1857 "siguió la Guerra de Tres Años porque esa Constitución no satisfizo a los liberales ni a los conservadores... Eso es precisamente lo que se trata de evitar en esta ocasión" (NE, t. I, p. 278). Este puede haber sido el argumento que unió a la coalición moderada, que cuenta con un núcleo duro de 23 diputados exrenovadores, pero que logra duplicar sus votos. No obstante, triunfa la coalición jacobina con un reiterado contraargumento que Mújica sintetiza: de seguirse formando a la juventud con "fanatismos y principios insanos, surgirán más tarde otras contiendas que ensangrentarán la Patria" (NE, t. I, p. 160).

En el artículo aprobado el término laico -cuyas connotaciones desataron tan grandes polémicas en la asamblea- queda ambiguo, pues permite aplicar la ley con cierta flexibilidad entendiéndose como enseñanza neutral frente a las creencias religiosas del hogar o como educación que trasmite la

\section{()(1) $\$$}


verdad basada en criterios científicos y por tanto lucha contra la superstición aprendida en casa. Acaso esta ambigüedad fue deliberada, producto de las negociaciones que entabló Mújica en asamblea privada para construir una mayoría. Lo cierto es que esta ambigüedad cedió ante sucesivas reformas constitucionales que darían a la educación nuevos contenidos: racionalista, socialista, democrática.

\section{BAJO EL ESPECTRO DE LA GUERRA}

Consagrar el derecho a la educación resulta inútil si no se asegura que los niños asistan a la escuela. Sin embargo, un problema común en el siglo XIX, que se agrava durante la lucha armada, es que los niños no acuden a las instituciones educativas fundamentalmente porque sus padres requieren de su ayuda en las labores productivas. Son muy pocos los menores de edad que se forman en las aulas, pero aún son menos los que concluyen sus estudios. Las estadísticas de 1907 de la Secretaría de Fomento registran que apenas 8\% de los alumnos inscritos concluyen la educación primaria (NE, t. I, p. 188). Por este motivo, el 19 de enero la asamblea aprueba -sin discusión y por unanimidad de votos- una nueva obligación para los mexicanos: los padres y tutores están obligados a que sus hijos o pupilos asistan a las escuelas públicas o privadas para recibir la educación primaria elemental e instrucción militar (art. 31, frac. I). En cuanto la instrucción de las clases populares se considera un asunto de vital importancia para "el porvenir y engrandecimiento de nuestra patria”, la comisión incrementa la edad de los menores que deben asistir a la escuela de diez años - que propuso el proyecto de reformas- a quince e indica que habrá sanciones para los padres que infrinjan la ley (NE, t. II, p. 1227). Así, el precepto constitucional logra, por lo menos en papel, la obligatoriedad educativa por la que se había afanado Justo Sierra.

El Congreso recupera de la Constitución de 1857 -y aprueba sin debate- otras obligaciones para los mexicanos: sostener al Estado contribuyendo con los gastos públicos (art. 31, frac. IV) y alistarse y servir en la Guardia Nacional en caso de trastornos internos o guerra extranjera (art. 31, frac. III). El proyecto de reformas de Carranza introduce otra obligación para los nacionales -que la asamblea admite también sin discusión- recibir en el municipio en que residan instrucción cívica y militar para que se mantengan "aptos en el ejercicio de los derechos de los ciudadanos, diestros en el manejo de armas y conocedores de la disciplina militar" (art. 31, frac. II), (NE, t. II, p. 1228). De

\section{()(1) $(3$}


este modo, la educación laica se extiende a los adultos mediante la formación ciudadana al tiempo que se fortalece la Guardia Nacional, antigua institución republicana del ciudadano en armas, institución de alcances nacionales sin injerencia de la Iglesia, que en el siglo xix propició entre los milicianos una cultura política laica que respaldó a los gobiernos federalistas.

Las circunstancias por las que atraviesa el país favorecen que el constituyente introduzca la educación ciudadana y la disciplina militar en la vida cotidiana de niños y adultos, pues la guerra civil aún no ha concluido: las guerrillas villistas y zapatistas continúan activas. En el escenario internacional la situación es compleja. La asamblea tiene presente la tensa relación con Estados Unidos debido a la invasión al puerto de Veracruz (abril-noviembre de 1914) y estando reunido el Congreso permanecen en Chihuahua 10000 soldados estadunidenses de la expedición comandada por John Pershing, en represalia por el ataque de Pancho Villa a Columbus, Nuevo México.

Los diputados -entre ellos Mújica- se muestran convencidos que la jerarquía eclesiástica mexicana prepara una nueva intervención armada con el respaldo del clero estadunidense (NE, t. I, p. 139). El persistente rumor se basa en que la mayoría de los prelados mexicanos se exilió en Estados Unidos donde encontró apoyo en los obispos de aquel país, y desde allá continuaron su campaña de denuncia sobre "el problema religioso en México" (Ramírez Rancaño, 2002, pp. 71 y 295). Palavicini, que presume ser un hombre informado en los secretos de la diplomacia, indica que el secretario de Estado estadunidense "Lansing es un hombre de curia" y el secretario particular de Woodrow Wilson, Tumulty, es un católico fanático, agente de las intrigas clericales en el círculo íntimo de ese presidente (NE, t. III, p. 2532). De hecho, en las negociaciones para que el gobierno de aquel país otorgara el reconocimiento de jure al constitucionalismo, Wilson exigió una vida democrática y garantías a los católicos. Por si fuera poco, la Gran Guerra divide a Europa, aunque -según el testimonio de Molina Enríquez (2001)- "pasa inadvertida" para la mayoría de los congresistas (p. 404).

\section{LIBERAR A LAS MUJERES COMO SE HA LIBERADO A LOS NIÑOS}

Las dos comisiones de reformas a la Constitución -fue necesario instalar el 23 de diciembre de 1916 una segunda comisión para poder dictaminar todas las modificaciones propuestas por Carranza- temen que los debates sobre la

\section{()(1) $\circledast$}


libertad de conciencia y sobre las relaciones del Estado con la Iglesia sean tan largos y polémicos como fue el debate sobre el derecho a la educación, por eso lo posponen. Ante las presiones ejercidas por algunos miembros de la coalición jacobina, la asamblea fija fecha para debatir ambos temas, el 27 de enero, sólo cuatro días antes de concluir las sesiones del Congreso.

La asamblea -sin debate y por unanimidad de votos- retoma la herencia liberal para proteger a la libertad religiosa: "Todo hombre es libre para profesar la creencia religiosa que más le agrade y para practicar las ceremonias, devociones, actos de culto respectivo en los templos o en su domicilio particular, siempre que no constituyan un delito o falta penados por la ley" (art. 24). El constitucionalismo mexicano introdujo una progresiva restricción al culto externo. La Ley de Libertad de Cultos (1860) previó que todo acto solemne que se llevara a cabo en un espacio público requería el permiso de la autoridad política (art. 11), pues las manifestaciones religiosas en lugares destinados al uso común "es a todas luces una cuestión de policía" que compete a la autoridad civil (p. 955). El proyecto de reformas de Carranza reitera la reglamentación de las Leyes de Reforma. Para asegurar que todo acto religioso quede confinado en los templos, la primera comisión de reformas -en su dictamen del 3 de enero- al corregir el estilo del proyecto añade "los cuales estarán siempre bajo la vigilancia de la autoridad” (NE, t. I, p. 969). La voluntad de los diputados por secularizar la sociedad, sin embargo, no deja de afectar extensas regiones del país en las que la vida social y cultural se organiza en torno a la parroquia y las manifestaciones piadosas de barrios, pueblos y ciudades.

Las más radicales propuestas en contra de la Iglesia católica emergen en el debate. Palavicini (1987) recuerda a Enrique Recio como un "obrero yucateco perfectamente ignorante y exaltado anticlerical" (vol. 1, p. 163), pero es él quien somete un voto particular el 4 de enero 1917 que propone varias adiciones a la libertad de culto. Primera, sólo los mexicanos por nacimiento puedan ejercer el sacerdocio porque considera que a los sacerdotes extranjeros -en particular a los españoles- les ha faltado cariño por las instituciones republicanas. Es posible que sus vivencias como miembro de una Iglesia protestante favorezcan su segunda propuesta: los ministros de cultos deberán estar casados civilmente si son menores de 50 años de edad, ya que el celibato perpetuo "es sencillamente una irrisión", que los religiosos no cumplen "llevando la ignominia y la desolación a los hogares". Su tercera propuesta -quizá influenciada por su iglesia- consiste en prohibir el sacramento católico de la confesión (NE, t. I, p. 970).

\section{()(1) $(9$}


El principal argumento en contra del sacramento de la penitencia es de orden político: el clero "ha cogido la confesión secreta para conspirar contra el Gobierno y contra las instituciones republicanas" -según señala González Galindo-. Este diputado justifica uno de los gestos iconoclastas que caracterizaron a las fuerzas constitucionalistas en 1914-1915:

Los jefes revolucionarios que entraron triunfantes en cada pueblo de la República, vinieron sacando los confesionarios y quemándolos públicamente, y esto lo hacían porque estaban conscientes de que los ministros de la religión católica habían cogido aquel mueble para conspirar contra la revolución, contra el Constitucionalismo; $y$ todos ustedes, los que anduvieron en la revolución, están conformes con ello (NE, t. III, p. 2541).

No fue un mero exceso en la violencia revolucionaria, sino que en algunas regiones fue una política sistemática. El gobernador de Nuevo León, Antonio I. Villarreal, el 23 de julio de 1914 expidió un decreto que prohibió la confesión auricular (Correa, 1991, p. 210); lo mismo hizo en Chiapas el general José Agustín Castro el 14 de diciembre del mismo año; en el Estado de México también fue prohibida, mientras que en San Luis Potosí se requirió que un inspector del gobierno estuviera presente durante la confesión de los feligreses (Fallaw, 2013, p. 94).

Para los constitucionalistas más radicales este sacramento amenaza la estructura patriarcal familiar. Recio argumenta que la vida privada de los cónyuges queda bajo la fiscalización del sacerdote de modo que "la confesión sienta a una autoridad distinta a la del jefe de familia y esto es sencillamente abominable" (NE, t. I, p. 970). En el México revolucionario la idea de la confesión como un instrumento político del clero actualiza tres estereotipos comunes en el anticlericalismo del mundo católico: el voto del celibato deprava a los sacerdotes; las mujeres que son las que acuden al sacramento de redención son excepcionalmente vulnerables en el confesionario y la confesión es una influencia corruptora que amenaza la estabilidad doméstica (Fallaw, 2013, p. 129), imágenes ampliamente difundidas por la prensa y literatura anticlerical que tienen como representante icónico a Emilio Zola.

Acorde con estos estereotipos, los más débiles, los niños y las mujeres, son los que están más expuestos a la influencia del fanatismo, por eso González Galindo señala "ya hemos arrebatado al clericalismo la niñez con el artículo $3^{\circ}$, ¿por qué no hemos de arrebatar a la mujer del confesionario, ya que le arrebata el honor de su hogar valiéndose de la confesión auricular?" (NE, t. III, p. 2542).

\section{()(1) $(9$}


En el pleno, la voz de Lizardi se impone con pragmáticos argumentos. El matrimonio de los sacerdotes, aunque coincide con Recio en que es una acción moralizadora, no tendrá los resultados deseados porque los clérigos burlarán la ley divorciándose. La confesión católica como el onanismo le parece inmoral, pero señala que es muy difícil impedir que una persona le cuente a otra lo que ha hecho y evitar que le pida consejo. Haciendo eco a la cultura patriarcal, añade que el mal no está en que los sacerdotes quieran confesar, sino en que el jefe de familia lo permita y remata afirmando enérgicamente "en mi casa, mando yo". Consigue así aplausos nutridos y la mayoría de votos requerida para desechar las adiciones propuestas (NE, t. I, pp. 978-979), pero no deja de ser notable que $42.57 \%$ de los votos respalden las propuestas de Recio (Marván, 2006, t. I, p. 991).

\section{LA IGLESIA, ENEMIGO DEL PUEBLO}

La segunda comisión de reformas -integrada con Paulino Machorro, Andrés Méndez, Hilario Medina y Heriberto Jara-, al elaborar su dictamen sobre las relaciones del Estado con la Iglesia, enfrenta la difícil tarea de mediar entre dos posiciones antagónicas: la moderada que defiende las libertadas individuales acotadas por las Leyes de Reforma y la jacobina, que se inclina por "desfanatizar a la sociedad" y entre sus miembros más radicales se encuentra Recio que -como se ha señalado-buscó incluso reformar materia del católico derecho canónico.

Esta tarea se confía al conciliador Medina, estrecho colaborador de Carranza, que se desempeñó en el gobierno de Veracruz como encargado de la Secretaría de Relaciones Exteriores. Este abogado respetado por la facción jacobina, en el debate sobre la libertad de culto se reconoce como ateo y firme positivista $y$, sin embargo, defiende -como lo hizo Comte al fundar su religión que tuvo seguidores en México y Brasil-que las religiones tienen un aspecto moral -civilizatorio se diría hoy en día- "entre los individuos y los pueblos incultos", que resultan indispensables a las sociedades, porque "proveen los límites de orden y respeto" (NE, t. I, p. 987).

Es muy probable que antes de presentar el dictamen a la asamblea, Medina circulara un borrador para que otros lo enriquecieran y llegar al pleno con un documento previamente negociado. Así, el artículo incorpora la propuesta de Recio para exigir que los ministros de cultos sean mexicanos e incluye la idea de José Álvarez para desconocer la personalidad jurídica "de

\section{(1)(1)}


las asociaciones llamadas eclesiásticas" -cuya importancia se revisa más abajo (NE, t. III, p. 2546)-. Es posible que el presidente de la comisión aprovechara para acordar las reformas en la semana que media entre el 20 de enero -fecha en la que la comisión presenta el dictamen al pleno-y el 27 de enero en que se debate. Lo cierto es que ni el artículo ni el dictamen suscitan gran polémica en el pleno.

Consecuente con la función civilizatoria que Medina atribuye a la religión, el artículo 130 -originalmente numerado como 129- garantiza la libertad de conciencia e indica que "El Congreso no puede dictar leyes estableciendo o prohibiendo religión alguna", precepto que reproduce del proyecto de reformas de Carranza. El dictamen explica que "la ley respeta la creencia en el individuo y las prácticas que esa creencia impone también en el individuo", con ello garantiza a los creyentes que se respetarán todos y cada uno de los sacramentos cristianos, pues en 1914 y 1915 en algunas regiones los constitucionalistas no sólo prohibieron la confesión auricular sino que los gobernadores Antonio I. Villarreal en Nuevo León, Francisco Murgía en el Estado de México y Cándido Aguilar en Veracruz también prohibieron el matrimonio eclesiástico y el bautismo (Fallaw, 2013, p. 102). El artículo 130 reitera que el matrimonio es un contrato civil -como asentaron las Leyes de Reforma- y la constitucionalista Ley del Divorcio de 1915 refuerza que el vínculo conyugal, siendo un contrato, puede disolverse.

Una vez garantizada la libertad de culto, la comisión enfrenta el problema de "restringir el poder moral tan grande" del clero, que el Estado necesita vigilarlo para que no llegue a convertirse en un peligro para el mismo poder público (NE, t. III, p. 2534). La clave del dictamen está en que modifica el núcleo de las Leyes de Reforma. Mientras la legislación liberal proclamó la separación de la Iglesia y del Estado, el dictamen propone asegurar la supremacía del poder civil sobre toda asociación religiosa. La primera reconoció la personalidad jurídica de la Iglesia; el Constituyente de 1916-1917 se la niega. Más aún, al no reconocer personalidad jurídica a la Iglesia católica, tampoco reconoce a los ministros de los cultos, a los que considera como personas que ejercen una profesión, por lo que quedan sujetos a las leyes que en un futuro próximo se dicten sobre la materia. A petición de varios diputados, el dictamen faculta a las legislaturas de los estados para determinar el número de ministros que pueden ejercer, según las necesidades locales. A este poderoso control se añade la vieja prohibición que impide a cualquier orden monástica establecerse en México (art. $4^{\circ}$ ), que ratifica a las Leyes de Reforma, y por lo mismo el Congreso aprueba sin discusión y por unanimidad de votos.

\section{(1)(1)}


Un segundo aspecto innovador es que prohíbe al clero participar en la vida política para que los sacerdotes "no puedan hacer del poder moral de la creencia el apoyo de una tendencia política" (NE, t. III, p. 2534). Por eso, la Constitución niega a ministros y asociaciones religiosas sus derechos ciudadanos. El voto activo y pasivo y el derecho de reunión con fines políticos son estrictamente prohibidos. Restringe a la prensa confesional al prohibir que critiquen a las leyes fundamentales del país o al gobierno.

Mientras el pleno se prepara para el debate del artículo 130, la segunda comisión elabora los dictámenes de los artículos transitorios de la Constitución, que permitirán una controlada transición de la dictadura militar al orden constitucional. El primer jefe, tras promulgar la ley fundamental, inmediatamente convocará a elecciones para integrar los tres poderes federales. Al Congreso de la Unión esperan tres inmensas tareas: pacificar el país, iniciar la reconstrucción nacional y elaborar las leyes orgánicas, sin las cuales no se podrá llevar a la práctica las reformas revolucionarias. Por eso, la segunda comisión considera que es vital asegurar "cierta unidad de criterio revolucionario que el próximo Congreso constitucional tendrá con el Constituyente" -según señala el dictamen al artículo 16 transitorio (NE, t. III, p. 2654).

En lo inmediato con las restricciones a los derechos políticos del clero y laicos, la comisión cierra toda posibilidad a los católicos para reorganizarse y contender en el próximo proceso electoral con un partido político de denominación religiosa o apoyado por la Iglesia. La comisión seguramente teme la capacidad organizativa que demostró el Partido Católico Nacional durante el gobierno de Madero, pues obtuvo las gubernaturas de Jalisco y Querétaro y una significativa presencia en el Congreso de la Unión y en los congresos de los estados del centro de la república. Al legislar para el futuro, Medina se muestra satisfecho porque con el artículo 130 el clericalismo ha sido ahogado -según afirma en su discurso de clausura del Constituyente (Palavicini, 1987, vol. 2, p. 616).

En el debate destacan dos oradores: Mújica y Palavicini. Es posible que estando la reforma previamente acordada, con sus discursos buscan dejar una última constancia de sus posiciones. El general, formado en el seminario de Morelia, se define como librepensador. En el debate del artículo $3^{\circ}$ defendió a capa y espada que en las escuelas no se brinde instrucción religiosa alguna. En la discusión sobre las relaciones del Estado con las Iglesias pronuncia un muy largo discurso dirigido a la prensa internacional que asiste a las sesiones para que se "sepa allende del Bravo" las razones "que los mexicanos hemos tenido, no sólo para perseguir, sino aun para exterminar esa hidra

\section{()(1) $\$$}


que se llama clero" (NE, t. III, p. 2561). El general lee y comenta documentos extraídos del archivo episcopal de la Diócesis de Zamora -que desafortunadamente no fueron reproducidos en el Diario de los debates- pero se infiere a que con ellos busca ejemplificar la inmoralidad de los sacerdotes en sus prácticas religiosas y en su vida privada, así como "el tentáculo que tienen sobre la propiedad" (NE, t. III, p. 2563).

El director de El Universal, también librepensador aunque acusado por los jacobinos de clerical, se coloca en un horizonte más amplio: la Gran Guerra y la compleja relación entre México y Estados Unidos. Informa al pleno que el 25 de enero el presidente estadunidense manifestó al Senado de su país que "los Estados Unidos deben participar en los arreglos de la paz europea" y para que la paz sea estable y duradera "se incluya a los pueblos del Nuevo Mundo, porque Woodrow Wilson sigue hablando a nombre de toda la América, pues los yanquis siguen creyendo que América es toda suya" (NE, t. III, p. 2553). A la doctrina Monroe opone la defensa del idioma y de la religión católica, elementos constitutivos de la nacionalidad mexicana, porque "de no fortalecerse la nacionalidad se deja al pueblo mexicano sin defensa para la conquista fácil del yanqui” (NE, t. III, p. 2557).

Sin duda, la dinámica parlamentaria ha cambiado. El binomio moderados-jacobinos desaparece por completo. Los diputados que trabajaron en la Sección de Legislación Social y que en el debate del artículo $3^{\circ}$ se mostraron tan preocupados porque la nueva ley fundamental propicie la gobernabilidad de una ferviente sociedad católica, callan.

El discurso de Palavicini ofrece una pista que podría explicar parcialmente el cambio de actitud: la Gran Guerra. Carranza, en la segunda quincena de enero, rechaza el ofrecimiento del telegrama Zimmermann, que propuso que a cambio de aliarse a los imperios centrales, México recuperaría los territorios perdidos en 1848 en la guerra con Estados Unidos. Por un par de meses se logra mantener la misiva en secreto, pero en paralelo se incrementan las presiones del país vecino para que México abandone su posición neutral. Ante el complejo escenario internacional, es posible que los moderados cierren filas en la unidad revolucionaria y se vean obligados a aceptar preceptos que en las primeras sesiones del Congreso habrían rechazado.

Al votar el artículo 130, el Teatro Iturbide prácticamente se ha vaciado. La sesión pudo resultar excesivamente larga, acaso los diputados pierden interés en discutir un artículo que está previamente negociado, tal vez los anarcosindicalistas y en particular la diputación yucateca con el rechazo del voto particular de Recio, en protesta silente abandonan el recinto. En un espacio

\section{()(1)}


casi vacío, el presidente del Congreso, Luis Manuel Rojas, señala que al día siguiente dará a conocer el resultado de la votación. Esta no fue registrada en el Diario de los debates. Hoy en día se desconoce el número de diputados que aprobó la profunda transformación de las relaciones entre el Estado y las Iglesias.

\section{SIN EL TENTÁCULO SOBRE LA PROPIEDAD}

En el último día de sesiones del Congreso y en una sesión maratónica los diputados aprueban el artículo 27. En las primeras sesiones de la asamblea los grupos políticos se habían decepcionado de las reformas propuestas en el proyecto de Constitución sobre los derechos de los obreros, de los campesinos y el usufructo de las riquezas nacionales, que constituían la piedra de toque de las demandas revolucionarias. Tras ensayar varias estrategias, los diputados forman dos comisiones especiales no previstas en el reglamento. Una para redactar el capítulo del trabajo (art. 123) y la otra para el artículo 27; ambas son presididas por el diputado y secretario de Fomento, Pastor Rouaix. Las improvisadas asambleas logran construir los consensos indispensables entre los grupos políticos, pero no llevan minutas ni actas que permitan revisitar el proceso legislativo.

Inspirado el artículo 27 en el regalismo del siglo XVI, establece que "La Nación tendrá en todo tiempo el derecho de imponer a la propiedad privada las modalidades que dicte el interés público", de ahí se desprenden nuevas restricciones para las Iglesias.

Si bien el artículo 130 para evitar que los ministros de cultos acumulen bienes raíces, les impide heredar y considera al patrimonio eclesiástico como un bien nacional; el artículo 27 nacionaliza nuevamente los bienes de la Iglesia católica, como lo habían hecho las Leyes de Reforma. Los templos destinados al culto público así como los inmuebles eclesiásticos -obispados, seminarios, conventos, colegios y cualquier edificio- son declarados propiedad de la nación, el precepto constitucional puntualiza que se destinarán a servicios públicos de la federación o de los estados. Consecuente con la nacionalización, niega a las iglesias la capacidad de adquirir, poseer o administrar bienes raíces.

Tal y como se anunció en el debate del artículo $3^{\circ}$, el artículo 27 instituye que por ningún motivo la beneficencia pública o privada podrá estar bajo la dirección, patronato o administración de instituciones religiosas, minis-

\section{()(1) $\circledast$}


tros de cultos o de sus asimilados -así llama a los laicos de la Iglesia- y establece nuevos controles para que el clero no pueda hacerse de nuevos bienes a través de prestanombres (NE, t. I, p. 998).

El parco testimonio de Rouaix (1959) no refiere gran cosa sobre la manera en que construyó los consensos en materia de propiedad eclesiástica, quizá no tuvo necesidad y simplemente aprovecha una gran convergencia, pues - como se ha señalado-incluso la bandera del grupo moderado es endurecer la aplicación de las Leyes de Reforma. Por unanimidad de votos se aprueba el artículo 27.

\section{CONCLUSIONES}

Frente a las teorías clásicas de secularización que sostienen que los acelerados procesos de industrialización y urbanización condujeron a que en las sociedades occidentales disminuyeran las creencias religiosas - por lo menos su presencia en el espacio público-, Blancarte (2012) ha insistido que en México fue una conquista del siglo xix operada desde el ámbito político (p. 78). En efecto, una sociedad agraria, con un débil gobierno federal que no lograba controlar su territorialidad y asediada por los imperialismos estadunidense y europeo, logró con las Leyes de Reforma la supremacía del poder civil sobre el eclesiástico. Cerraron conventos y monasterios, los cementerios fueron secularizados, el registro civil y el matrimonio civil quedaron instituidos, el voto religioso se sustituyó por la simple promesa de decir verdad en los actos jurídicos y el culto se encerró en las iglesias, de modo que las prácticas religiosas quedaron confinadas a la esfera privada de los creyentes, restringiendo el carácter público y comunitario de las manifestaciones piadosas.

La separación Iglesia-Estado, y su consecuente secularización de la sociedad fue sólo una vertiente de un proyecto de nación mucho más amplio, que sintetizó Melchor Ocampo en su Manifiesto del Partido Liberal. Con la desamortización y venta de los bienes eclesiásticos se esperaba formar una sociedad de pequeños propietarios, un mercado nacional y pagar la deuda pública, con ello México lograría fortalecer su soberanía y romper el aislamiento internacional; los logros del proyecto juarista los he evaluado en otros trabajos (Luna Argudín, 2013).

En el Constituyente de 1916-1917 la secularización -como en el proyecto juarista- fue un eje transversal que penetra distintos ámbitos regulados por el Estado. Los diputados coincidieron en cerrar toda posibilidad a

\section{(1)(1)}


laicos y clérigos para reorganizarse dando forma a un movimiento similar al del catolicismo social cuyos alcances se manifestaron entre 1903 y 1914, pero difirieron en la forma de hacerlo. Un grupo político, representado por el propio Carranza y la facción moderada, defendió las libertades individuales de corte liberal y para restringir la influencia social eclesiástica sostuvo que bastaba con una severa implementación de las Leyes de Reforma. Es decir, concibieron las relaciones Iglesia y Estado como un problema esencialmente político. De hecho, la posición oficial del gobierno constitucionalista fue que "a los frailes" se les ha castigado por trabajar en contra del gobierno y de las instituciones, mas no porque sean sacerdotes -según afirmó Macías, uno de los redactores del proyecto de reformas a la Constitución (NE, t. I, p. 291).

En contraste, una amplia coalición de corte culturalista tenía prisa, mucha prisa. A diferencia de los constituyentes de 1856-1857 que confiaron en que el marco institucional paulatinamente transformaría a las masas de ilotas en una vigorosa ciudadanía (Arriaga, 1988), apostaron por otorgar al Estado un mayor control sobre la educación y desde el Estado transformar la cultura católica de la sociedad mexicana para formar un hombre nuevo, con nuevos valores y aptitudes cívicas, capaz de defender las conquistas revolucionarias.

Monzón -con la diputación yucateca- sostuvo el proyecto anarquista de la Escuela Nueva, mientras que la mayoría jacobina, sin un modelo pedagógico definido, creyó firmemente -como Rosas y Reyes- que al destruir a las escuelas católicas que formaban a los niños en la mansedumbre y en el servilismo, se podría formar "una raza nueva", que se guiara por la libertad de criterio, en la verdad y en la ciencia (NE, t. I, p. 226). Para Mújica estos hombres nuevos, que serían fruto de la revolución, darían forma a una nueva gobernabilidad, las diferencias ya no se resolverían por medio de las armas, sino que se zanjarían "en la tribuna, en los parlamentos, por medio del libro, por medio de la palabra, por medio del derecho" (NE, t. I, p. 160).

Concebido el pueblo mexicano como inculto, supersticioso y fanático, la empresa civilizatoria que se confirió al Estado no se agotó en la escuela sino que alcanzó a la Guardia Nacional para educar a los adultos con sus ejercicios cívicos y militares. La tarea civilizatoria que se abrogaron los constituyentes era de tal magnitud que una amplia coalición que sumó 70 diputados -entre ellos Mújica, Macías y Monzón- se propusieron combatir las costumbres y hábitos que conducían a la "degradación". Por eso insistieron en prohibir la venta de drogas y de bebidas alcohólicas, así como actividades y espectáculos considerados bárbaros -juegos de azahar, corridas de toros

\section{()(1) $(9$}


y peleas de gallos-. Aunque la iniciativa no fue aprobada porque afectaba los intereses económicos de los estados del centro (Palavicini, 1987, vol. 2, p. 602), muestra la amplia coincidencia en favor de que el Estado ejerciera una estrecha tutela sobre la población.

Derrotadas las propuestas anarcosindicalistas -la enseñanza racionalista, el matrimonio de los sacerdotes y la prohibición del sacramento de la penitencia-, los diputados entablan nuevas alianzas. Estas favorecieron un doble movimiento: la secularización de la sociedad se limitó a impedir la organización política de los católicos y a ejercer desde el gobierno una estrecha vigilancia sobre el clero. Pero también propició que el artículo 130 superara el modelo histórico de las Leyes de Reforma, que había reconocido jurídicamente a la Iglesia católica, mientras que la Constitución de 1917 se lo negó a todas las asociaciones religiosas y con ello pudo traspasar un límite que tradicionalmente el Estado había respetado: el gobierno interno de la Iglesia católica. Así reguló que el número de sacerdotes por estado, a los que se les consideró profesionistas, se les exigió que se registraran ante autoridad competente para ejercer su ministerio y se les exigió que fueran de nacionalidad mexicana.

La secularización impuesta desde el Estado rompió con el antiguo principio liberal de igualdad de los ciudadanos ante la ley al privar a los sacerdotes y laicos de todos sus derechos políticos. Esta radical medida tenía como antecedente la Constitución de 1857 -que negó al clero el voto y la participación política- se justificó entonces como un severo límite a la influencia social de la Iglesia católica en una ley fundamental que sólo se atrevió establecer la tolerancia de cultos, pero no la libertad de conciencia. El Congreso de 1917 volvió a justificar las medidas con la inmensa influencia social que ejercía el clero sobre las masas. En materia de propiedad, el Constituyente retomó la legislación de la reforma para nacionalizar de nueva cuenta las propiedades eclesiásticas.

Destacados representantes de la historiografía académica católica han considerado que las restricciones a la Iglesia católica dieron forma a un profundo autoritarismo en contra de la mayoría de la población. Para Meyer (1974) el Estado mexicano logró restablecer el Real Patronato que ejercían los reyes de España, dejando a la Iglesia sólo el dominio de la doctrina y de la devoción privada, pero el Estado que habría de aplicar este nuevo patronato era "agresivamente antirreligioso" y sus decisiones no tendrían apelación porque había roto relaciones con el Vaticano (p. 71). Romero de Solís (1994) sostiene que la ley fundamental de 1917 con el fortalecimiento del presidencialismo y las restricciones a la Iglesia estableció una dictadura constitucional. Frente a

\section{(1)(1)}


un constituyente que impuso verticalmente la secularización de la sociedad, el historiador opone el integrismo católico: la Iglesia es la institución "que engloba al hombre desde que nace hasta que muere, que penetra a los hogares y a las conciencias, que con sus normas de conducta puede hacer enfrentar al individuo al Estado" (p. 230). Esta no deja de ser una expresión contemporánea del "clericalismo" que Medina creyó haber truncado con el artículo 130.

En el cierre de sesiones del Constituyente el conciliador Medina creía que logró mediar entre las distintas posiciones que se expresaron en el Congreso, y lo que es más importante estaba convencido de haber alcanzado el equilibrio entre la libertad individual de conciencia y los límites impuestos a las Iglesias. Era tal su optimismo que en su discurso de clausura del Congreso señaló que eran cuatro las columnas del edificio constitucional: el artículo $3^{\circ}$, el $5^{\circ}$ que ha resuelto el problema del trabajo; el 24 que da solución al llamado problema religioso y el 129 "que ha dado una organización a esa clase que se llama clero". En conjunto dan forma a la reforma social (Palavicni, 1987, vol. 2, p. 616).

Muy pronto el endeble equilibrio mostró sus límites, el 24 de febrero de 1917 los arzobispos y obispos presentaron una enérgica protesta en contra de cada uno de los artículos constitucionales que aquí se han revisado. Tomaron nuevas formas y profundidad las tendencias "desfanatizadoras" posrevolucionarias: la reglamentación del artículo 130 detonaría una nueva guerra civil.

\section{LISTA DE REFERENCIAS}

Arriaga, P. (1988). Proyecto de Constitución. Dictamen de la comisión. En F. Tena Ramírez, Leyes fundamentales de México, 1808-1897 (pp. 525-594). México: Porrúa.

Bantjes, A. (2009). Mexican revolutionary anticlericalism: concepts and tipologies. The Americas, 65(4), 467-480. DoI: 10.1353/tam.0.0105

Blancarte, R. (2012). Religión y sociología: cuatro décadas alrededor del concepto de secularización. Estudios Sociológicos, 30, 59-81. Recuperado de http://estudiossociologicos.colmex.mx/index.php/es/article/view/185/185

Blidstein, M. (2000). Política y caudillismo en el Congreso Constituyente de 1917. Mexican Studies/Estudios Mexicanos, 16(1), 39-78. Dor: 10.1525/msem.2000.16.1.03a00020

Bojórquez, J. D. (2014). Crónica del Congreso Constituyente. México: SEP/INEHrm/Instituto de Investigaciones Jurídicas-UnAM.

Butler, M. (2004). Popular piety and political identity in Mexico's cristero rebellion. Michoacán 1927-29. Gran Bretaña: Oxford University Press.

\section{()(1) $(3$}


Ceballos Ramírez, M. (1991). El catolicismo social, un tercero en discordia. México: Colmex.

Convocatoria al Congreso Constituyente (2016). México: CIDE. Recuperado de http://programaconstitucion.cide.edu/documentos

Correa, E. (1991). El partido católico y sus directores. México: FCE.

Fallaw, B. (2013). The seduction of revolution: anticlerical campaigns against confession in Mexico, 1914-1935. Journal of Latinoamerican Studies, 45(1), 91-120. DoI: 10.1017/S0022216X12001216

García Ugarte, M. E. y Rosas Salas, S. F. (2016). La Iglesia católica en México desde sus historiadores (1960-2010). Anuario de Historia de la Iglesia, 25, 91-161. DoI 10.15581/007.25.91-191

Loyo, E. y Staples, A. (2012). Fin del siglo y de un régimen. En Historia mínima. La educación en México (pp. 127-158). México: Colmex.

Luna Argudín, M. (2013). Leyes de Reforma y república liberal, 1857-1880. En M. Suárez Cortina (ed.), México y España. Historia y memoria de dos siglos (1810-2010) (pp. 117-136). Santander: Universidad de Cantabria/Editorial Síntesis.

Mabry, D. J. (1978). Mexican anticlerics, bishops, cristeros, and the devout during the 1920s: A scholarly debate. Journal of Church and State, 20(1), 81-92. Recuperado de: http://historicaltextarchive.com/sections.php?action=read\&artid=135

Marván, I. (2012). Los constituyentes abogados en el Congreso 1916-1917 (Documentos de trabajo, 245). México: cIDE. Recuperado de http://repositorio-digital.cide.edu/ bitstream/handle/11651/1408/112407.pdf?sequence=1\&isAllowed $=y$

Marván Laborde, I. (2006). Nueva edición del Diario de los debates del Congreso Constituyente de 1916-1917 (3 vols.). México: Suprema Corte de Justicia.

Marván Laborde, I. (2007). ¿Cómo votaron los diputados constituyentes de 1916-1917? Política y Gobierno, XIV(2), 309-347. Recuperado de http://www.redalyc.org/articulo.oa?id=60327293001

Matute, A. (2008). El anticlericalismo, ¿quinta revolución? En F. Savarino y A. Mutolo (coords.), El anticlericalismo en México (pp. 29-37). México: Cámara de Diputados LX Legislatura/Miguel Ángel Porrúa/Tecnológico de Monterrey.

Mena, J. L. (1941). La escuela socialista, su desorientación y fracaso. El verdadero derrotero. México: s. e.

Meyer, J. (1974). La cristiada. Vol. 2. El conflicto entre la Iglesia y el Estado, 1926-1929. México: Siglo XXI.

Molina Enríquez, A. (2001). El pensamiento de la revolución, en los primeros diez años de su actividad, reducida a leyes precisas. En Andrés Molina Enríquez: con la revolución a cuestas. México: FCE.

Palavicini. F. (1987). Historia del Congreso Constituyente (2 vols.). México: INEHRM.

\section{()(1) $\$$}


Ramírez Rancaño, M. (2002). La reacción mexicana y su exilio durante la revolución de 1910. México: Miguel Ángel Porrúa/Instituto de Investigaciones Sociales-unAM.

Reformas al Reglamento Interior del Congreso de la Unión. (2006). En Nueva edición del Diario de los debates del Congreso Constituyente de 1916-1917 (t. III, pp. 28532898). México: Suprema Corte de Justicia.

Romero de Solís, J. M. (1994). El aguijón del espíritu. Historia contemporánea de la Iglesia católica en México (1892-1992). México: Instituto Mexicano de Doctrina Social Cristiana.

Rouaix, P. (1959). Génesis de los artículos 27 y 123 de la Constitución política de 1917. México: INEHRM.

Smith, P. (1973). La política dentro de la revolución, el Congreso Constituyente de 1916-1917. Historia Mexicana 22(3:87), 363-395.

Ulloa, Berta (1979). Historia de la revolución mexicana. Parte 2. Periodo 1914-1917. Vol. 4. La revolución escindida. México: Colmex.

Urías Horcasitas, B. (2008). El poder de los símbolos/los símbolos en el poder: teosofía y "mayanismo" en Yucatán (1922-1923). Relaciones, XXIX(115), 179-212. Recuperado de http://www.revistarelaciones.com/files/revistas/115/pdf/beatrizUriasHorcasitas.pdf

\section{OTRAS FUENTES}

Curley, R. (2009). Anticlericalism and public space in revolutionary Jalisco. The Americas, 65(4), 511-534. DoI: 10.1353/tam.0.0107

Discurso de don Venustiano Carranza (2014). En J. Castañón y A. Morales Jiménez (comps.), 50 discursos doctrinales en el Congreso Constituyente de la república mexicana, 1916-1917 (pp. 3-25). México: SEP/INEHRM.

Ley electoral para la formación del Congreso Constituyente de los Estados Unidos Mexicanos (2016). México: Cámara de Diputados. 